Revista Perspectivas Online: Exatas \& Engenharias Anais do V Seminário P\&D PROVIC/PIBIC

II Encontro de Iniciação Científica CNPq Vol. 10, n² 29, Suplemento, 2020

\title{
Dimensionamento de uma turbina a gás de eixo axial através de programas de fluidodinâmica computacional
}

\author{
Matheus Mattos Pereiral $^{l}$, Silvio Eduardo Teixeira da Silva ${ }^{2}$ \\ (1) Aluno de Iniciação Científica do PIBIC/ISECENSA - Curso de Engenharia Mecânica; (2) Pesquisador Orientador - Laboratório de Análise e \\ Projeto de Sistemas Mecânicos - LAPSIM/ISECENSA, Rua Salvador Correa, 139, Centro, Campos dos Goytacazes, RJ, Brasil.
}

Com o crescimento industrial e elevada demanda por produção de energia, se faz necessário a utilização de máquinas e equipamentos que correlacionam dimensão, custo e eficiência. As turbinas a gás são elementos fundamentais em diversas aplicações indústrias e são compostas fundamentalmente por compressor, câmara de combustão e turbina. Esse projeto tem como finalidade principal dimensionar o compressor que é responsável por aumentar a pressão do fluido, utilizando-se de programas de fluidodinâmica computacional e equações essenciais como conservação de energia, continuidade e quantidade de movimento. Durante o processo de compressão do fluido, foram determinadas temperatura, pressão, densidade e área de seção transversal do difusor para cada um dos estágios presentes no equipamento. Foram utilizados balanços de energia e condições isentrópicas a fim de descrever os processos intrínsecos do escoamento do ar durante o processo de compressão e da expansão dos gases no interior do compressor. A partir destes resultados, foi iniciado o processo de modelagem das palhetas rotoras e estatoras através da ferramenta BladeGen presente no Software Ansys. Comprovou-se que para atender a taxa de compressão necessária no compressor é fundamental uma quantidade de treze estágios, como também que há uma variação nos projetos das lâminas das palhetas em cada um deles. Desta forma, é possível concluir que a simulação atinge seu objetivo para a maioria das condições físicas a ela aplicadas, pois possui um compromisso com a realidade dos fenômenos que ela tenta descrever.

Palavras-chave: Energia Elétrica. Compressor. Simulação.

Instituição de Fomento: PIBIC; ISECENSA. 